\title{
Safety and Feasibility of Dobutamine-Atropine Stress Echocardiography for the Diagnosis of Coronary Artery Disease in Diabetic Patients Unable to Perform an Exercise Stress Test
}

\author{
Abdou Elhendy, Md, PHD \\ RON T. VAN DOMBURG, MSC \\ Don Poldermans, MD, PHD \\ JEROEN J. BAX, MD, PHD
}

\author{
Peter R. Nierop, md \\ Marcel L. Geleijnse, MD \\ JOS R.T.C. ROELANDT, MD, PHD
}

OBJ ECTVE - Dobutamine stress testing is increasingly used for the diagnosis and functional evaluation of coronary artery disease. However, little is known about the safety and feasibility of this stress modality in diabetic patients.

RESEARCH DESIGN AND METHODS - We studied the impact of diabetes on hemodynamic profile and on the safety and feasibility of dobutamine (up to $40 \mu \mathrm{g} \cdot \mathrm{kg}^{-1} \cdot \mathrm{min}^{-1}$ ) and atropine (up to $1 \mathrm{mg}$ ) stress echocardiography for the diagnosis of coronary artery disease in 1,446 consecutive patients (aged $60 \pm 12$ years, 962 men) with limited exercise capacity and suspected myocardial ischemia. Of these, 184 patients were known to have IDDM or NIDDM. The test was considered feasible when $85 \%$ of the maximal heart rate and/or an ischemic end point (new or worsened wall motion abnormalities, ST segment depression, or angina) was achieved.

RESULTS - No myocardial infarction or death occurred during the test. There was no significant difference between diabetic and nondiabetic patients with regard to heart rate increase during dobutamine stress echocardiography ( $58 \pm 25$ vs. $61 \pm 24$ beats/min), peak rate pressure product $(18,400 \pm 3,135$ vs. $18,048 \pm 4454)$, or the prevalence of hypotension (systolic blood pressure drop of $>40 \mathrm{mmHg}$ ) ( $7 \mathrm{vs.} 5 \%$ ), ventricular tachycardia (5.4 vs. $4.5 \%$ ), and supraventricular tachycardia ( 3 vs. $4 \%$ ) during the test. Dobutamine stress echocardiography was feasible in $92 \%$ of the diabetic patients and in $90 \%$ of the nondiabetic patients. Coronary angiography was performed in 55 diabetic and 240 nondiabetic patients. Sensitivity, specificity, and accuracy of dobutamine stress echocardiography for the diagnosis of coronary artery disease in diabetic patients were 81,85 , and $82 \%$. Those in nondiabetic patients were 74,87 , and $77 \%$, respectively (NS).

CONCLUSIONS - Dobutamine stress echocardiography is a feasible method for the diagnosis of coronary artery disease in patients with limited exercise capacity with a comparable safety, feasibility, and accuracy in diabetic and nondiabetic patients.

Diabetes C are 21:1797-1802, 1998

From the Thoraxcenter, University H ospital Rotterdam-Dijkzigt, Erasmus University, Rotterdam, the Netherlands. Address correspondence to Abdou Elhendy, MD, PhD, Thoraxcenter, Ba 300, Dr Molewaterplein 40, 3015 GD Rotterdam, the N etherlands.

Received for publication 15 September 1997 and accepted in revised form 15 July 1998.

Abbreviations: DSE, dobutamine-atropine stress echocardiography; OR, odds ratio.

A table elsewhere in this issue shows conventional and Système International (SI) units and conversion factors for many substances.

an increas ronary artery disease is the leading cause of death in diabetic patients 1-3). The Framingham Study showed an increased incidence of myocardial infarction, angina, and sudden death in diabetic patients, particularly in women, and the risk was independent of the usual risk factorsfor coronary artery disease (3). Therefore, noninvasive diagnosis of coronary artery disease in diabetic patients is important for planning a management strategy and for the selection of patients for coronary angiogra phy and possible revascularization. Exercise stress testing is the most common stress modality used for the noninvasive evaluation of coronary artery disease. However, exercisetolerance in diabetic patients may be impaired, particularly because of the higher prevalence of peripheral vascular disease. Dobutamine-atropine stress echocardiography (DSE) is an accurate and safe al ternative method that is increasingly used for evaluation of coronary artery disease in patients unable to perform an adequate exercise test (4-7). The potential advantages of this technique in diabetic patients are the ability to define the early onset of myocardial ischemia in absence of symptoms due to autonomic neuropathy (8) and the ability to localize and quantify the amount of myocardial ischemia and the extent of coronary artery disease. Despite the established safety, feasibility, and accuracy of DSE for the diagnosis of coronary artery disease (9-13), these results have not been confirmed in diabetic patients. The presence of diabetic neuropathy can potentially alter thechronotropic and the inotropic response to dobutamine, and thereby reduce the ability of the test to induce myocardial ischemia or impair the compensatory mechanisms in response to dobutamine-induced hypotension, leading to a reduced feasibility of the test $(8,14)$. Diabetic patients with clinical or subclinical autonomic neuropathy are at 
higher risk of ventricular arrhythmias and sudden death (15). Therefore, the safety of administration of a high dose of an arrhythmogenic drug like dobutamine should be evaluated, particularly knowing that alarge number of patients subjected to this test have left-ventricular dysfunction that may provide a substrate for arrhythmias (16). We have recently shown that hypertensive patients are more likely to develop dobuta mineinduced hypotension (13), and therefore, the propensity to develop hypotension in diabetic patients may also be increased because of the higher prevalence of hypertension in diabetic patients. Another confounding characteristic of diabetic patients is the occurrence of left-ventricular dysfunction in the absence of significant coronary artery disease (17), which may complicate echocardiographic interpretation of wall motion abnormalities during the test. The aim of this study is to evaluate the safety, feasibility, and hemodynamic response to dobutamine-atropinestress testing in diabetic patients with suspected myocardial ischemia who are unable to perform exercise stress testing.

\section{RESEARCH DESIGN AND METHODS}

\section{Patient population}

Thestudy population comprised 1,446 consecutive patients with limited exercise capacity who had been referred to our imaging laboratory for evaluation of myocardial ischemia by DSE. Of these patients, 184 had an established diagnosis of diabetes according to World Health O rganization criteria (18) (group 1). There were 40 patients with IDDM and 144 patients with NIDDM. Group 2 comprised 1,262 nondiabetic patients. Contraindications for DSE were severe heart failure, significant val vular heart disease, severe hypertension (blood pressure $\geq 180 / 110$ ), hypotension (blood pressure $<90 / 60$ ), and unstable chest pain. Mean age was $60 \pm 12$ years (962 men). All patients gave a verbal informed consent to undergo the study. The Hospital's ethical committee approved the use of DSE for evaluation of patients with known or suspected coronary artery disease.

\section{Dobutamine stress test}

Dobutaminewas infused through an antecubital vein starting at a dose of $5 \mu \mathrm{g} \cdot \mathrm{kg}^{-1}$. $\min ^{-1}$ followed by $10 \mu \mathrm{g} \cdot \mathrm{kg}^{-1} \cdot \mathrm{min}^{-1}$ (3min stages), increasing by $10 \mu \mathrm{g} \cdot \mathrm{kg}^{-1}$. $\min ^{-1}$ every 3 min to a maximum of $40 \mu \mathrm{g}$. $\mathrm{kg}^{-1} \cdot \mathrm{min}^{-1}$. Atropine (up to $1 \mathrm{mg}$ ) was given to patients not achieving $85 \%$ of agepredicted maximal heart rate, and dobutamine infusion was continued (19). The electrocardiogram was monitored throughout dobutamine infusion and recorded each minute. Cuff blood pressure was measured at rest, every 3 min during stress, and at maximal stress. The test was interrupted if severe chest pain, ST-segment depression $>2 \mathrm{~mm}$, significant ventricular or supra ventricular arrhythmia, hypertension (blood pressure $\geq 240 / 120$ ), systolic blood pressure fall $>40 \mathrm{mmHg}$, or any intolerableside effect regarded as being due to dobutamine occurred during the test. Metoprolol (1-5 $\mathrm{mg}$ ) was available and was used intra venously to reverse the effects of dobutamine if they did not revert quickly. The test was considered feasible if the patient could achieve $85 \%$ of the maximal heart rate pre dicted for age and/or when an ischemic end point (angina, ST-segment depression, new or worsened wall motion abnormalities) was reached.

\section{Stress echocardiography}

Echocardiographic images were acquired at rest and during stress and recovery. The echocardiograms were recorded on video tapes and were also digitized on optical disk and displayed side-by-side in quadscreen format (Vingmed-CFM 800; Vingmed Sound A/S, Horten, Norway) to facilitate the comparison of rest and stress images. The left ventricular wall was divided into 16 segments and scored using a four-point scale, where $1=$ normal, $2=$ hypokinesis, $3=$ akinesis, and $4=$ dyskinesis. Wall motion score index was derived by dividing the sum of individual scores for the 16 segments by 16 (19). The interpretation of images was performed by two experienced observers without knowledge of the patients' clinical data. In case of disagreement, a majority decision was achieved by a third observer. In our laboratory, the inter- and intraobserver agreements for DSE assessment are 92 and 94\%, respectively (20). Ischemia was defined as new or worsening wall motion abnormalities. As we have previously concluded (21), ischemia was not considered when akinetic segments at rest became dyskinetic during stress without improvement at lowdose dobutamine $\left(5-10 \mu \mathrm{g} \cdot \mathrm{kg}^{-1} \cdot \mathrm{min}^{-1}\right)$.

\section{Coronary angiography}

Coronary angiography was performed within 3 months from DSE in 295 patients.
Lesions were quantified as previously described (22). Significant coronary artery disease was defined as a diameter stenosis $\geq 50 \%$ in $\geq 1$ major epicardial arteries. Coronary arteries were assigned to myocardial segments as previously described (7). The peri-infarction zone was defined as myocardial segments in the distribution of infarct-related artery (6).

Statistical analysis

Unless specified, data are presented as mean values $\pm S D$. The $\chi^{2}$ test was used to compare differences between proportions. The Student's t test was used for analysis of continuous data. Stepwise logistic regression models were fitted to identify independent predictors of hypotension. The difference in risk was expressed as an odds ratio (OR) with the corresponding $95 \% \mathrm{Cl}$. Differences were considered significant if the null hypothesis could be rejected at the 0.05 probability level. Sensitivity, specificity, and accuracy of DSE for the diagnosis of significant coronary artery disease were derived according to standard definitions and were presented with the corresponding $95 \% \mathrm{Cl}$.

\section{RESULTS}

Clinical characteristics

Patient characteristics, medications, and indications of stress testing in both groups are presented in Table 1. Patients of group 1 had a higher prevalence of a history of hypertension, myocardial infarction, and congestive heart failure and were receiving diuretics and angiotensin-converting enzyme inhibitors more commonly than patients of group 2. Among the 144 patients with NIDDM, 24 (17\%) were not receiving antidiabetic medication, 80 (56\%) were receiving oral antidiabetic drugs, and 40 $(28 \%)$ were receiving insulin (in 32 patients as monotherapy and in 8 patients combined with oral antidiabetic drugs).

\section{Symptoms and hemodynamic}

response

Therewas no death or myocardial infarction during or shortly (24 h) after the test. Systolic blood pressure and heart rate increased significantly from rest to peak stress (133 \pm 25 [range 90-180] vs. $135 \pm 30$ [60-280] $\mathrm{mmHg}, \mathrm{P}<0.00005$, and $73 \pm 14$ [41-130] vs. $133 \pm 16$ [64-212] beats/min, $\mathrm{P}<0.00001$ ), whereas diastolic blood pressure decreased significantly $(76 \pm 13$ [45-110] vs. $71 \pm 16$ [35-130] $\mathrm{mmHg}, \mathrm{P}<$ 
Table 1- Clinical features of diabetic (group 1) and nondiabetic (group 2) patients ungteing DSE

\begin{tabular}{lccc}
\hline & & & \\
& Group 1 & Group 2 & P value \\
\hline $\mathrm{n}$ Clinical features & 184 & 1,262 & - \\
$\quad$ Age (years) & $60 \pm 10$ & $60 \pm 12$ & 1 \\
$\quad$ Males & $118(64)$ & $844(67)$ & 0.5 \\
Previous myocardial infarction & $110(60)$ & $641(49)$ & $<0.01$ \\
History of heart failure & $41(22)$ & $183(15)$ & $<0.01$ \\
History of hypertension & $89(48)$ & $467(37)$ & $<0.005$ \\
Medications & & & \\
$\quad$ 3-blockers & $58(32)$ & $444(35)$ & 0.3 \\
$\quad$ Calcium channel blockers & $74(40)$ & $445(35)$ & 0.2 \\
$\quad$ Nitrates & $76(41)$ & $458(36)$ & 0.2 \\
$\quad$ ACE inhibitors & $84(46)$ & $408(32)$ & $<0.0005$ \\
$\quad$ Diuretics & $60(33)$ & $280(22)$ & $<0.005$ \\
Indications for stress testing & & & \\
$\quad$ Typical chest pain & $60(33)$ & $401(32)$ & 0.8 \\
$\quad$ Atypical chest pain & $46(25)$ & $367(29)$ & 0.3 \\
$\quad$ Exertional dyspnea or fatigue & $17(9)$ & $125(10)$ & 0.8 \\
$\quad$ Assessment after myocardial infarction & $61(33)$ & $369(29)$ & 0.3 \\
$\quad$ or revascularization & & & \\
\hline
\end{tabular}

Data are means \pm SD or $n(\%)$.

$0.00005)$. Atropinewas administered in 649 patients (45\%), and the mean dose was similar in both groups $(0.60 \pm 0.29$ vs. $0.60 \pm$ $0.28 \mathrm{mg}$ ). Atropine induced a significant comparable increase of heart rate in both groups (Table 2). Heart rate, systolic and diastolic blood pressures, and rate pressure product were higher in group 1 at rest and similar for both groups at peak stress. The prevalence of symptoms and arrhythmias was similar in both groups (Table 3). There was no significant difference between the two groups with regard to percentage of patients reaching the target heart rate or the prevalence of various types of arrhythmias (Table 3). Ventricular tachycardia was terminated in all cases spontaneously by stopping dobutamine infusion or administration of metoprolol. Systolic blood pressure drops of $>40 \mathrm{mmHg}$ occurred in 71 patients $(5 \%)$ during stress. Multivariate analysis identified baseline systolic blood pressure $>140$ $\mathrm{mmHg}$ (OR 7.2, 95\% Cl 3.5-16), older age (OR 1.03, 95\% Cl 1.02-1.09), and medication with calcium channel blockers $(O R$ 1.8, $95 \% \mathrm{Cl} 1.2-3.4)$ as independent predictors of hypotension. Hypotension was the reason for test termination in only 30 of the 71 patients who developed hypotension. Reasons for termination of the test are shown in Table 4. The test was considered feasible (achievement of $85 \%$ of maximal heart rate and/or an ischemic end point) in 169 patients in group $1(92 \%)$ and in 1,142 patients in group $2(90 \%)(P=0.8)$.

\section{Stress echocardiography}

Wall motion abnormalities were present at rest in 125 patients in group 1 (68\%) and in

Table 2- Hemodynamic data of diabetic (group 1) and nondiabetic (group 2) patients urgting DSE

\begin{tabular}{lccc}
\hline & & & \\
& Group 1 & Group 2 & P value \\
\hline $\mathrm{n}$ & 184 & 1,262 & - \\
Hemodynamic and stress test variables & & & \\
$\quad$ Heart rate at rest (beats/min) & $76 \pm 14$ & $72 \pm 14$ & $<0.0001$ \\
Heart rate at peak stress (beats/min) & $134 \pm 17$ & $133 \pm 16$ & 0.3 \\
Systolic blood pressure at rest (mmHg) & $137 \pm 26$ & $132 \pm 22$ & $<0.01$ \\
Systolic blood pressure at peak stress $(\mathrm{mmHg})$ & $137 \pm 30$ & $135 \pm 29$ & 0.6 \\
Diastolic blood pressure at rest $(\mathrm{mmH})$ & $77 \pm 13$ & $75 \pm 13$ & 0.06 \\
Diastolic blood pressure at peak stress $(\mathrm{mmHg})$ & $70 \pm 15$ & $71 \pm 16$ & 0.4 \\
Rate pressure product at rest & $10,507 \pm 3,135$ & $9,521 \pm 2,412$ & $<0.00001$ \\
Rate pressure product at peak stress & $18,400 \pm 3,135$ & $18,048 \pm 4,454$ & 0.3 \\
Heart rate before atropine* (beats/min) & $112 \pm 23$ & $111 \pm 23$ & 0.5 \\
Heart rate after atropine* (beats/min) & $136 \pm 19$ & $134 \pm 18$ & 0.3 \\
Systolic blood pressure before atropine* $(\mathrm{mmHg})$ & $131 \pm 28$ & $131 \pm 25$ & 1 \\
Systolic blood pressure after atropine* $(\mathrm{mmHg})$ & $134 \pm 25$ & $131 \pm 28$ & 0.3 \\
Systolic blood pressure drop $>20 \mathrm{mmHg}$ & $38(21)$ & $225(18)$ & 0.4 \\
Systolic blood pressure drop $>40 \mathrm{mmHg}$ & $12(7)$ & $59(5)$ & 0.3 \\
Maximal dobutamine dose $\left(\mu \mathrm{mg} \cdot \mathrm{kg}^{-1} \cdot \mathrm{min}-1\right)$ & $36.5 \pm 7.2$ & $37 \pm 6.4$ & 0.4 \\
Atropine given & $87(47)$ & $562(45)$ & 0.5 \\
ST-segment depression & $36(20)$ & $172(14)$ & $<0.05$ \\
\hline
\end{tabular}

Data are means $\pm S D$ or $n(\%) . *$ Data are taken only from patients who received atropine. 
Table 3- Symptoms and arrhythmias in diabetic (group 1) and nondiabetic (group 2) patientspatients with inadequate chronotropic during dobutamine-atropine stress echocardiography

\begin{tabular}{lccc}
\hline & Group 1 & Group 2 & P value \\
\hline $\mathrm{n}$ Symptoms/arrhythmias & 184 & 1,262 & - \\
$\quad$ Nausea & $7(4)$ & $58(5)$ & 0.6 \\
Flushing & $0(0)$ & $11(0.9)$ & 0.2 \\
Dizziness & $5(3)$ & $36(3)$ & 0.9 \\
Anxiety & $3(2)$ & $27(2)$ & 0.7 \\
Chills & $7(4)$ & $48(4)$ & 1 \\
Headache & $4(2)$ & $57(5)$ & 0.1 \\
Symptomatic hypotension & $1(0.5)$ & $17(1)$ & 0.4 \\
Typical angina & $48(26)$ & $307(24)$ & 0.6 \\
Premature atrial contractions & $13(7)$ & $90(7)$ & 0.9 \\
Premature ventricular contractions & $63(34)$ & $397(31)$ & 0.4 \\
Supraventricular tachycardia & $5(3)$ & $51(4)$ & 0.4 \\
Atrial fibrillation & $2(1)$ & $17(1)$ & 0.8 \\
Ventricular tachycardia $<10$ beats & $8(4)$ & $48(4)$ & 0.7 \\
Ventricular tachycardia $\geq 10$ beats & $2(1)$ & $9(0.07)$ & 0.6 \\
\hline
\end{tabular}

Data are $n(\%)$.

CONCLUSIONS - To our knowledge, this is the first study to evaluate the impact of diabetes on the safety, feasibility, and diagnostic accuracy of DSE in a large series of patients. Our study demonstrates that DSE is a feasible and safe method for evaluation of coronary artery disease in diabetic patients with suspected myocardial ischemia and limited exercise capacity. No myocardial infarction or death occurred during the test. Despite the fact that diabetic patients had more severe left-ventricular dysfunction at rest, the feasibility and safety profile were similar in diabetic and nondiabetic patients. Ventricular tachycardia was terminated in all cases spontaneously by stopping dobutamine infusion or administration of metop rolol. Minor side effects, including chills, dizziness, flushing, headache, nausea, and anxiety, were common and occurred in $18 \%$ of theentire population. However, these symptoms were usually well tolerated and were the reason for termination of the test in a minority of patients $(0.07 \%)$. The prevalence of these side effects was similar in dia betic and nondiabetic patients.

Hemodynamic response of diabetic patients to dobutamine

Heart rate increased significantly and equally in patients with and without diabetes, and therewas no significant difference between the two groups with regard to age, sex, or the maximal dobutamine dose. This implies that the chronotropic response to high-dose dobutamine is not impaired in diabetic patients. Borow et al. (23) have previously reported that in normotensive young adults with diabetes and no evidence of coronary artery disease, the contractile response to low-dose dobutamine infusion $\left(5 \mu \mathrm{g} \cdot \mathrm{kg}^{-1} \cdot \mathrm{min}^{-1}\right)$ was similar to that of normal subjects despite the occurrence of ejection fraction drop during exercise in $45 \%$ of diabetic patients. Despite the reported parasympathetic dysfunction in diabetic patients (16), atropine induced a similar increase of heart rate in diabetic and nondiabetic patients in our study, denoting the feasibility of the administration of this parasympatholytic agent in achieving a significant increase of heart rate in diabetic response to high-dose dobutamine. There was a modest but significant increase of systolic blood pressure in nondiabetic patients from rest to peak stress, whereas this failed to increase in diabetic patients. This may be explained by the higher baseline systolic blood pressure and the higher frequency of medication with angiotensin-converting enzyme inhibitors in diabetic patients. Both factors have been implicated in impairment of blood pressure response to dobutamine $(13,24)$. Peak systolic blood pressure and rate pressure product were similar in patients with and without diabetes, denoting the achievement of a similar hemodynamic stress required to provoke myocardial ischemia. The prevalence of symptomatic and asymptomatic hypotension was similar in diabetic and nondiabetic patients. Independent predictors of hypotension were medication with calcium antagonists, baseline systolic blood pressure $\geq 140 \mathrm{mmHg}$, and older age, which are in accordance with previous studies (13).

Comparison with previous studies Bates et al. (25) studied 53 patients with IDDM by DSE before kidney and/or pancreatic transplantation. During a follow up period of $418 \pm 269$ days, cardiac event rates were $54 \%$ among patients with abnormal DSE and $6 \%$ among those with normal DSE by retrospective analysis. The dobutamine stress test was terminated prematurely because of hypotension in one patient and nauseain another. Theincidence of arrhythmias during the test was not reported. In our study, the prevalence of different types of arrhythmias during dobutamine stress testing was similar in diabetic and nondiabetic

Table 4- Reasons for termination of dobutamine stress testing in diabetic (group 1) and nondiabetic (group 2) patients

\begin{tabular}{lccc}
\hline & Group 1 & Group 2 & P value \\
\hline $\mathrm{n}$ & 184 & 1,262 & - \\
Reasons for test termination & & & \\
$\quad$ 85\% of maximal heart rate & $148(80)$ & $1,028(81)$ & 0.7 \\
Maximal dose & $11(6)$ & $99(8)$ & 0.4 \\
Angina & $14(7)$ & $59(5)$ & 0.09 \\
ST changes & $1(0.5)$ & $15(1)$ & 0.4 \\
Arrhythmias & $5(3)$ & $20(2)$ & 0.3 \\
Hypertension & $1(0.5)$ & $1(0.01)$ & 0.1 \\
Hypotension & $3(1.7)$ & $27(2.1)$ & 0.7 \\
Dyspnea & $0(0)$ & $3(0.2)$ & 0.5 \\
Chills, flushing, anxiety, dizziness & $1(0.05)$ & $10(0.07)$ & 0.7 \\
\hline
\end{tabular}

Data are $n(\%)$. 
Table 5- Accuracy of ischemic pattern at dobutamine stress echocardiography for the diagnosis of significantrery artery stenosis in diabetic (group 1) and nondiabetic (group 2) patients without previous myocardial infien

\begin{tabular}{|c|c|c|c|c|c|}
\hline Diagnostic parameters & Group 1 & $\begin{array}{c}\text { Number of } \\
\text { patients }\end{array}$ & Group 2 & $\begin{array}{c}\text { Number of } \\
\text { patients }\end{array}$ & $P$ value \\
\hline \multicolumn{6}{|l|}{ Overall diagnosis (all patients) } \\
\hline Sensitivity & $77(58-95)$ & $10 / 13$ & $73(61-85)$ & $24 / 33$ & 0.8 \\
\hline Specificity & $86(70-101)$ & $6 / 7$ & $86(77-95)$ & $19 / 22$ & 1 \\
\hline Accuracy & $80(62-98)$ & $16 / 20$ & $78(67-89)$ & $43 / 55$ & 0.9 \\
\hline Sensitivity in patients with single-vessel disease & $67(41-92)$ & $4 / 6$ & $67(52-81)$ & $12 / 18$ & 1 \\
\hline Sensitivity in patients with multivessel disease & $86(67-104)$ & $6 / 7$ & $80(67-93)$ & $12 / 15$ & 0.8 \\
\hline \multicolumn{6}{|c|}{ Diagnosis of multivessel disease by multivessel ischemic pattern } \\
\hline Sensitivity & $57(35-79)$ & $4 / 7$ & $53(40-67)$ & $8 / 15$ & 0.9 \\
\hline Specificity & $85(69-100)$ & $11 / 13$ & $90(82-98)$ & $36 / 40$ & 0.6 \\
\hline Accuracy & $75(56-94)$ & $15 / 20$ & $80(69-91)$ & $44 / 55$ & 0.6 \\
\hline
\end{tabular}

Data are $\%(95 \% \mathrm{Cl})$ or $\mathrm{n}$.

patients. Theoverall preval ence of sup raventricular tachycardia (including atrial fibrillation) $(4.8 \%)$ and ventricular tachycardia $(4.8 \%)$ in our study is consistent with that reported by Mertes et al. (9) $(4.1 \%$ and $4.2 \%$ respectively). Arrhythmias were the reason for termination of the test in $2 \%$ of patients in our study, which is comparable to the findings of Mertes et al. (2.1\%). There was no difference between diabetic and nondiabetic patients regarding the feasibility of dobutaminestress testing. Overall feasibility $(91 \%)$ is comparable to that reported by Poldermans et al. (11) (98\%), Cornel et al. (10) (97\%), and Picano et al. (12) (88\%).
Accuracy of dobutamine stress echocardiography in diabetic and nondiabetic patients

To our knowledge, this is the first study that compares the diagnostic accuracy of DSE in diabetic and nondiabetic patients. Sensitivity, specificity, and accuracy were fairly comparable in both groups for the overall diagnosis of coronary artery disease, singlevessel disease, and multivessel disease, identification of multivessel disease on the basis of inducible ischemia in $>1$ vascular territory, and in the diagnosis of infarct-related and remote coronary artery stenosis. Therefore, the diagnostic accuracy of DSE was not limited in diabetic patients, despite the more severe baseline left-ventricular dysfunction. In thestudy by Bates et al. (25), 17 diabetic patients underwent coronary angiography. DSE had a sensitivity of $90 \%$ (9 of 10 patients) and a specificity of $86 \%$ (6 of 7 patients). However, the number of patients in that study was small, and the coronary angiogram was performed late after DSE in some patients (up to 557 days).

Limitations of the study

Diabetic and nondiabetic patients were not comparable with regards to clinical characteristics (hypertension, medications, and

Table 6- Accuracy of ischemic pattern at dobutamine stress echocardiography for the diagnosis of significantreary artery stenosis in diabetic (group 1) and nondiabetic (group 2) patients with previous myocardial infarction

\begin{tabular}{|c|c|c|c|c|c|}
\hline Diagnostic parameters & Group 1 & $\begin{array}{c}\text { Number of } \\
\text { patients }\end{array}$ & Group 2 & $\begin{array}{c}\text { Number of } \\
\text { patients }\end{array}$ & $P$ value \\
\hline \multicolumn{6}{|l|}{ Overall diagnosis (all patients) } \\
\hline Sensitivity & $83(70-95)$ & $24 / 29$ & $74(67-80)$ & $113 / 153$ & 0.3 \\
\hline Specificity & $83(71-96)$ & $5 / 6$ & $88(83-92)$ & $28 / 32$ & 0.8 \\
\hline Accuracy & $83(70-95)$ & 29/35 & $76(70-83)$ & $141 / 185$ & 0.4 \\
\hline Sensitivity in patients with single-vessel disease & $60(31-89)$ & $3 / 5$ & $61(50-71)$ & $34 / 56$ & 1 \\
\hline Sensitivity in patients with multivessel disease & $88(76-99)$ & $21 / 24$ & $81(75-88)$ & 79/97 & 0.5 \\
\hline \multicolumn{6}{|c|}{ Diagnosis of multivessel disease by multivessel ischemic pattern } \\
\hline Sensitivity & $50(39-61)$ & $12 / 24$ & $49(42-57)$ & $48 / 97$ & 1 \\
\hline Specificity & $82(69-95)$ & 9/11 & $91(87-95)$ & $80 / 88$ & 0.3 \\
\hline Accuracy & $60(44-76)$ & $21 / 35$ & $69(62-76)$ & $128 / 185$ & 0.3 \\
\hline \multicolumn{6}{|l|}{ Infarct-related artery } \\
\hline Sensitivity & $71(56-86)$ & $22 / 31$ & $61(54-68)$ & $93 / 152$ & 0.3 \\
\hline Specificity & $75(61-89)$ & $3 / 4$ & $85(80-90)$ & $28 / 33$ & 0.6 \\
\hline Accuracy & $71(56-86)$ & $25 / 35$ & $65(58-72)$ & $121 / 185$ & 0.5 \\
\hline \multicolumn{6}{|l|}{ Remote coronary artery } \\
\hline Sensitivity & $72(57-87)$ & $18 / 25$ & $67(60-74)$ & 70/104 & 0.7 \\
\hline Specificity & $90(80-100)$ & $9 / 10$ & 89 (84-93) & $72 / 81$ & 0.9 \\
\hline Accuracy & $77(63-91)$ & $27 / 35$ & $77(70-83)$ & $142 / 185$ & 1 \\
\hline
\end{tabular}


baseline left-ventricular function). However, the safety profile was similar in diabetic and nondiabetic patients despite the more severe left ventricular dysfunction and the higher prevalence of hypertension in diabetic patients. We did not study the autonomic function in diabetic patients, and therefore, we were not able to assess the correlation between the autonomic function and safety of the test. Coronary angiography was performed only in 295 patients $(20 \%)$. However, this is one of the largest studies correlating the findings at DSE with coronary angiography. Finally, the results of the test were available for the treating physicians with possible referral bias for coronary angiography, a factor that may reduce the specificity of the test by referring more patients with a positive rather than a negative test for angiography. However, specificity in nondiabetic patients is unlikely to be underestimated compared with that in diabetic patients because the latter have an established risk factor for coronary artery disease and a possibly higher rate of referral of patients with a positive test for coronary angiography.

Clinical implications and conclusions It is concluded that DSE is a safe and feasible method for evaluation of coronary artery disease with a comparable chronotropic response, safety, feasibility, and diagnostic accuracy in diabetic and nondiabetic patients.

Acknowledgments - This study was supported in part by the Department of Cardiology, Cairo University Hospital, Cairo, Egypt, and by a grant from the Netherlands Organization of Foreign International Cooperation in Higher Education (NUFFIC), the Hague, the Netherlands.

\section{References}

1. Janka HU: Increased cardiovascular morbidity and mortality in diabetes mellitus: identification of high risk factors. Diabetes Res Clin Pract SuppB0:85-88, 1996

2. Bell DS: Diabetes mellitus and coronary artery disease. Coron Aitery Dis 7:715-722, 1996

3. Kannel WB: Lipids, diabetes and coronary artery disease: insights from the Framingham Study. Am Heart J 110:1100-1107, 1985

4. Sawada SG, Segar DS, Ryan T, Williams R, Fineberg NS, Armstrong WF, Feigenbaum
$\mathrm{H}$ : Echocardiographic detection of coronary artery disease during dobutamine infusion. Circulation83:1605-1614, 1991

5. Elhendy A, Geleijnse ML, Roelandt JRTC, Cornel JH, van Domburg RT, El-Refae $M$, Ibrahim MM, El-Said GM, Fioretti PM: Assessment of patients after coronary artery bypass grafting by dobutamine stress echocardiography. Am J Cardiol 77:12341236, 1996

6. Elhendy A, van Domburg RT, Roelandt JRTC, Geleijnse ML, Cornel JH, El-Said GM, Fioretti PM: Accuracy of dobutamine stress echocardiography for the diagnosis of coronary artery stenosis in patients with myocardial infarction: the impact of extent and severity of left ventricular dysfunction. Heart 76:123-128, 1996

7. Marwick TH, D'Hondt AM, Baudhuin T, Willemat A, Wijns W, Detry J, Melin J: Optimal use of dobutamine stress for the detection and evaluation of coronary artery disease: combination with echocardiography, scintigraphy or both? J Am Coll Cadiol 22:159-167, 1993

8. Marchant B, Umachandan V, Stevensen R, Kopelman PG, Timmis AD: Silent myocardial ischemia: role of subclinical neuropathy in patients with and without diabetes. J Am Coll Cadiol22:1433-1437, 1993

9. Mertes H, Sawada SG, Ryan T, Segar DS, Kovacs R, Foltz J, Feigenbaum H: Symptoms, adverse effects and complications associated with dobutamine stress echocardiography: experience in 1118 patients. Circulation88:15-19, 1993

10. Cornel JH, Balk AHMM, Arnese M, Maat PW M, Elhendy A, Salustri A, Ten Cate FJ, Fioretti PM: Safety and feasibility of dobutamine-atropine stress echocardiography in patients with ischemic left ventricular dysfunction. J Am Soc Echocatiogr 9:27-32, 1996

11. Poldermans D, Fioretti PM, Boersma E, Forster T, Urk H, Cornel JH, Arnese M, Roelandt JRTC: Safety of dobutamine atropine stress echocardiography in patients with suspected coronary artery disease. Am J Cardiol73:456-459, 1994

12. Picano E, Mathias W Jr, Pingitore A, Bigi R, Previtali M: Safety and tolerability of dobutamine-atropine stress echocardiography: a prospective multicenter study. Lancet 344:1190-1192, 1994

13. Elhendy A, van Domburg RT, Roelandt JRTC, Geleijnse ML, Ibrahim MM, Fioretti PM: Safety and feasibility of dobutamineatropine stress testing in hypertensive patients. Hypertensioß9:1232-1239, 1997

14. Oikawa N, Umetsu M, Toyota T, Goto Y: Q uantitative evaluation of diabetic autonomic neuropathy by using heart rate variation: relation between cardiac para- sympathetic or sympathetic damage and clinical conditions. Tobuko J Exp Med48: 125-133, 1986

15. Kahn JK, Sisson JC, Vinic Al: QT interval prolongation and sudden cardiac death in diabetic autonomic neuropathy. J Clin Endocrinol Metal64:751-754, 1987

16. Aronson D: Pharmacologic modulation of autonomic tone: implications for the diabetic patient. Diabetologiaf0:476-481, 1997

17. Kannel WP, Hjortland M, Castelli WP: Role of diabetes in congestive heart failure: The Framingham Study. Am J Cardiol34:29-34, 1974

18. World Health Organization: Diabetes Melli tus: Report of aW HO Study @ap Geneva, World Health Org., 1985 (Tech. Rep. Ser. no. 727)

19. Elhendy A, Geleijnse ML, Roelandt JRTC, van Domburg RT, Nierop PR, El-Said GM, Fioretti PM: Evaluation by quantitative 99m-technetium MIBI SPECT and echocardiography of myocardial perfusion and wall motion abnormalities in patients with dobutamine-induced ST-segment elevation. Am J Cardiol 76:441-448, 1995

20. Bellotti P, Fioretti PM, Forster T, McNeill AJ, El-Said EM, Salustri A, Roelandt JRTC: Reproducibility of the dobutamine-atropine echocardiography stress test. Echocardiog raphy 10:93-97, 1993

21. Elhendy A, Cornel JH, Roelandt JRTC, van Domburg RT, Nierop PR, El-Said GM, Fioretti PM: Relation between contractile response of akinetic segments during dobutamine stress echocardiography and ischemia assessed by simultaneous 201 thallium SPECT. Am J Cardiol77:955-959, 1996

22. Baptista J, Arnese M, Roelandt JRTC, Fioretti P, Keane D, Escaned J, Boersma E, Di Mario C, Serruys PW: Quantitative coronary angiography in the estimation of the functional significance of coronary stenosis: correlation with dobutamine-atropine stress test. J Am Coll Cadiol23:1434-1439, 1994

23. Borow KM, Jaspan JB, Williams KA, Neumann A, Wolinski-Walley P, Lang RM: Myocardial mechanics in young adult patients with diabetes mellitus: effects of afterload, inotropic state and dynamic exercise. J Am Coll Cadiol15:1508-1517, 1990

24. Tanimoto M, Pai RG, Jintapakorn W, Shah PM: Mechanism of hypotension during dobutamine stress echocardiography in patients with coronary artery disease. Am J Cardiol76:26-30, 1995

25. Bates JR, Sawada SG, Segar DS, Spæedy AJ, Petrovic O, Fineberg NS, Feigenbaum HF, Ryan T: Evaluation using dobutamine stress echocardiography in patients with insulin dependent diabetes mellitus before kidney and/or pancreas transplantation. Am J Car . diol77:175-179, 1996 